\title{
Modification of the Sheehan Knee Arthroplasty for Additional Replacement of the Femoropatellar Articulation
}

\author{
R. Miehlke ${ }^{1}$ and H.W. Croon ${ }^{2}$ \\ 'Orthopaedic University Hospital Münster (Director: Prof. Dr.H. H. Matthiaß), Hüfferstr.27, D-4400 Münster/Westf., \\ Federal Republic of Germany \\ ${ }^{2}$ Twente University of Technology, Department of Medical Engineering, P.O. Box 217, NL-7500 AE Enschede, The Netherlands
}

Summary. An alternative version of the Sheehan knee arthroplasty is presented allowing additional replacement of the patellofemoral joint as there is a definite need for replacement of this part of the knee joint in osteoarthritis. However, the original Sheehan design which is considered to be one of the best compromises amongst semiconstrained knee prostheses does not offer this possibility. The design of the modification follows the design criteria of the original Sheehan knee and attempts to restore the necessities of normal patella function. Loading tests on the modified prosthesis were carried out prior to clinical trials. Surgical technique and additional aligning instruments are described. The clinical series comprises 16 cases up to now and no complications occurred so far. The indication is strictly limited to advanced osteoarthritis of the knee.

Zusammenfassung. Eine Modifikation der SheehanKniegelenksendoprothese, die den zusätzlichen Ersatz des femoropatellaren Gelenks gestattet, wird vorgestellt. Die Notwendigkeit der prothetischen Versorgung der Patella bei fortgeschrittener Gonarthrose ist unzweifelhaft, andererseits bot aber die Sheehan-Prothese dazu keine Möglichkeit. Diese an der Orthopädischen Universitätsklinik Münster seit 1975 eingeführte Methode sollte jedoch nicht verlassen werden, da sie unseres Erachtens bis heute einen der gangbarsten Kompromisse unter den Gleitachsprothesen des Kniegelenkes darstellt. Die Formgebung der Modifikation orientierte sich einerseits an den vorgegebenen Kriterien der Originalprothese und versucht zum anderen eine möglichst normale Patellafunktion wiederherzustellen. Die vor Beginn der klinischen Versuchs-

Offprint requests to: Dr. R. Miehlke (address see above) serie durchgeführten mechanischen Tests ließen keine Materialermüdung erkennen. Das operative Vorgehen und die Zusatzinstrumente werden erläutert. Der 1978 begonnene klinische Versuch umfaßt bisher 16 Fälle, bei denen keinerlei operationstechnische Schwierigkeiten oder postoperative Komplikationen auftraten. Die Indikation für diese Modifikation beschränkt sich ausschließlich auf Fälle von schwerer Gonarthrose mit besonderem Betroffensein des femoropatellaren Gelenkabschnitts. Aufgrund unserer bisher gesammelten Erfahrungen stellen wir jetzt diese Modifikation als sinnvolle Alternative zur Diskussion.

Since McKeever in 1955 [24] has reported on a device for artificial replacement of the patella made from vitallium and stated good early results in 40 patients many authors felt that patellar prosthetic replacement either alone or in combination with different femorotibial prostheses would lead to acceptable results concerning pain relief and preservation of satisfactory strength of the extensor mechanism as compared with patellectomy.

At the Orthopaedic University Hospital Münster Groeneveld et al. [14] in 1971 introduced a wedgeshaped plastic patella prosthesis combined with Platt, MGH, Lunceford or Sbarbaro femoral components $[22,32,35,41]$ and plastic tibial plateaus, thus realizing a non-linked total knee arthroplasty. In 1973 Groeneveld [15] reported on patella prostheses in addition to the Walldius knee [43] and in a different shape to the GUEPAR prosthesis [2]. He found far better overall results when patella replacement was used: $64 \%$ very good and good results against $46 \%$ when the femoro- 
tibial joint was replaced alone. In his series with no patella replacement Deburge points at remaining patellar pains to be an unsolved problem in GUEPAR knee arthroplasty [9]. And in connexion with non-constrained knee prostheses it was also felt by Bargren and Freeman [5] and by Lacey [19] that better results might be possible, if in addition the patellofemoral compartment would be included.

Hanslik [16], De Palma [10], Levitt [20] and Vermeulen [42] also achieved favourable results with McKeever or modified McKeever prostheses. Hanslik used a plastic McKeever type. However, the fixation of the device by a screw was not accepted on a larger basis. Elsewhere cement fixation of the patella was tried, only Groeneveld chose three non-cemented pegs plugged into the patella remainder.

Today rather a large number of different patella prostheses is available. Some are developed for femoropatellar resurfacing only, consisting of a metal component for the femoral groove and a polyethylene patella: Bechtol [6], Blazina [7], Lubinus [21]. But these devices are also compatible with most types of bi- or monocondylar knee implants. Worrel [44] designed a metal patella using no femoral counterpart but admits the necessity of a femoral component because of degenerative changes of the patellar bed. He therefore developed a plastic femoral prosthetic replacement too. Aglietti et al. [1] presented a polyethylene and metal patella to be used as such or in combination with different types of total condylar replacements. In the last years femoropatellar replacement incorporated in a total knee joint implant has also become more and more common: Attenborough [3], Freeman [13], Thomas [40], Insall and Ranawat [18], Coventry [8], RMCknee [34]. Some of these authors already report on encouraging early results.

Amongst a long term follow-up study of 122 cases of total knee joint replacements Miehlke [26, 28] surveys 34 cases with additional patella replacement in combination with hinged knees, mainly the GUEPAR knee. The average follow-up time was 4 years, 11 months ( $\min$. 2.3 years, max. 9.0 years). In this series we found postoperatively that 19 knees were absolutely pain-free in the patellofemoral compartment, the other 15 cases still showed some pain, but less severe than preoperatively, first of all preexisting pain at rest could be cured. On the other side these results do not indicate any longer such favourable results as found by Groeneveld [15] in the same material related to the overall results. This fact is in all probability due to the uniaxial movement of the femorotibial implant. As the GUEPAR knee has a rather dorsally positioned hinge, it opens widely on the anterior side when flexion increases, therefore exerting high stresses on the patella. Principal problems have also been stated by Ritter [33]. Radio- graphically osteolytic alterations of the patella remainder below the implant also confirm these experiences though they never caused complications [27]. After all we believed that results of femoropatellar replacement could be improved in combination with a design which imitates knee movement in a more physiological way.

When it was decided in early 1975 at the Orthopaedic University Hospital Münster to leave the hinged knees in favour of a not rigidly linked knee, the Sheehan prosthesis [38] was considered to be the best compromise amongst the new developments at that time. The results reported by Miehlke [29] are so far satisfactory. The large personel series of Sheehan [38] showing his results between 1971 and 1977 exhibits very good overall results and only little complications, first of all no loosenings, which justifies our choice.

In our opinion the only lack in the design considerations of this prosthesis is the fact that patellofemoral replacement was not taken into consideration. In most rheumatic patients patella problems occur far less then in osteoarthritic patients. In the contrary to Sheehan (personal communication) we have a considerably higher percentage of osteoarthritic knees $(55 \%)$ and therefore a need for additional prosthetic replacement of the patella. Furthermore the combination of an artificial patella with this type of knee joint implant seemed to promise a greater success in comparison with the hinged knees. For these reasons a modification of the Sheehan knee was developed allowing the patellofemoral compartment to be also replaced in cases of advanced generalized arthrosis of the knee joint, especially complicated by severe changes of the femoropatellar articulation.

\section{Design}

As the femoral component of the Sheehan knee has to be aligned to the distal femur from the posterior aspect of the condyles, the main interest in the design of a modified femoral component was to determine the most suitable distances between the stem and the back of the anterior flange, which is necessary for resurfacing the femoral groove. In this connexion the question had to be answered, how many different sizes would be sufficient to meet the whole variety of individual knees. With reference to design considerations Seedhom et al. [36], Erkman and Walker [12], Mensch and Amstutz [25], and Zöfelt [45] already have investigated the dimensions of the human knee either by radiographic measurements or on cadaver knees and Aglietti et al. [1] studied the size of the human patella radiographically.

In order to verify these results and with respect to our demands measurements were taken from $50 \mathrm{ca}-$ 


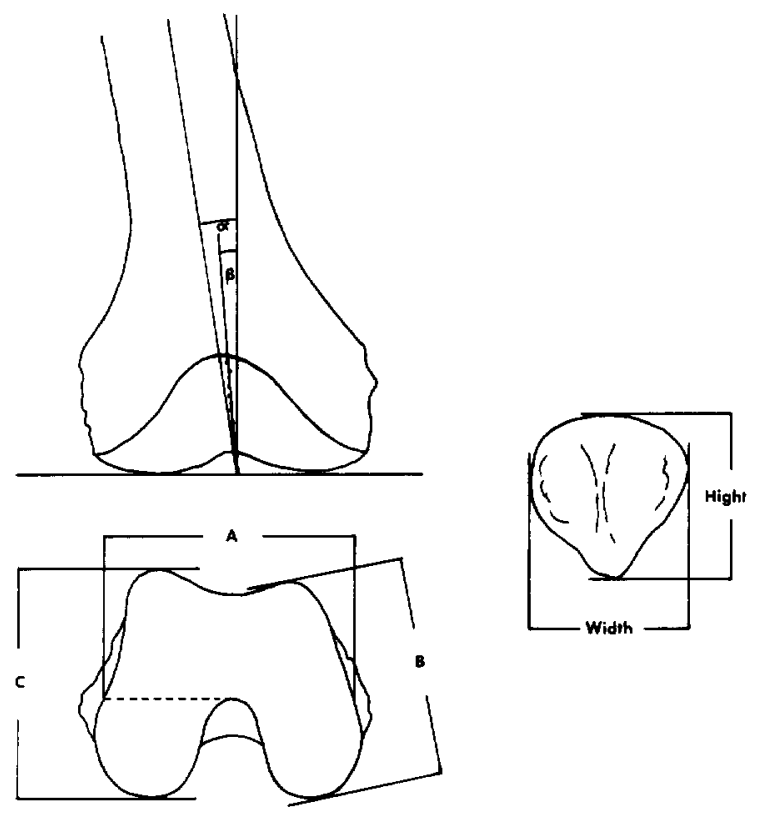

Fig. 1. Fifty cadaver femora and patellae were measured. The width of the condyles was measured at the level of the intercondylar notch (A). B represents the depth of the medial condyle and $C$ the depth of the lateral condyle. $a$ represents the valgus angle of the knee and $\beta$ the angle between the line of communication of the deepest points of the patellar groove and the condylar plane. The patellar width and height were measured. The size of the patella prosthesis was reduced to the articular surface

daver femora and 50 cadaver patellae. The following parameters were taken from the femora: width of the condyles in the frontal plane (A) and depth of the medial condyle (B) as well as the lateral condyle (C) in the sagittal plane. Then the femoro-condylar angle $(\alpha)$, i.e. the valgus angle, and the angle between the condylar plane and the line of communication of the deepest points of the patellar groove $(\beta)$ were measured. It was sufficient for the patellae to have the measurements of the height and the width in the frontal plane. The parameters are demonstrated in Fig. 1.

The cadaver specimen did not show any alterations influencing the results, such as arthritic osteophytes or condylar collapse.

The width of the femoral condyles amounted to a value of $77.29 \mathrm{~mm}$ with a standard deviation (SD) of 5.90. The medial condyles had an average depth of $62.75 \mathrm{~mm}, \mathrm{SD}=4.62$ and for the lateral condyles the value was $65.46 \mathrm{~mm}, \mathrm{SD}=4.23 . a$ averaged to $8.8^{\circ}$, $\mathrm{SD}=1.64$ and $\beta$ was $3.53^{\circ}, \mathrm{SD}=2.60$. The height and width of the patellae came out to be $42.77 \mathrm{~mm}$, $\mathrm{SD}=3.08$ on an average and $43.34 \mathrm{~mm}, \mathrm{SD}=2.70$ respectively. These results are in close correspondance with the values found in literature.

Based on these measurements two different sizes of femoral components with a distance between the back of the flange and the prosthetic stem of $8 \mathrm{~mm}$ for the

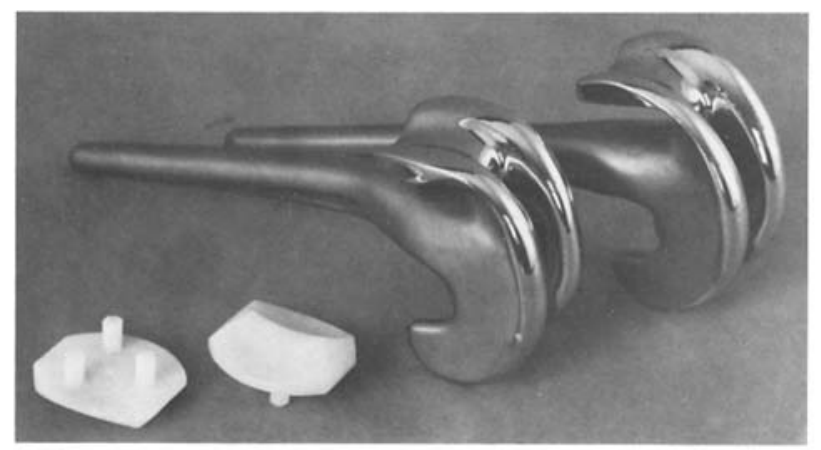

Fig. 2. Showing both sizes of the femoral components (standard size in front) and the patella (articulating surface and back with the three fixation pegs)

standard component and $11 \mathrm{~mm}$ for the large component seemed to be adequate, as careful alignment of the prosthesis from the posterior side of the femur is not disturbed. The amount of resection necessary on the anterior aspect of the distal femur depends on this manner of adjustment. However, small differences in size on the anterior side of the femur could be produced in comparison with the condylar depth of the individual knee. This fact is neglectable and can be compensated within certain limits by the amount of patella resection. In general it is advisable to use the standard component as far as possible.

The patella is available in one size and is compatible with both sizes of the femoral component. The height of the implant is $36 \mathrm{~mm}$ and the width $34 \mathrm{~mm}$. The gliding surface of the patellar component duplicates to a certain extent the natural patella crest and the medial and lateral facette. But on the other hand it depends on the possibilities of the design of the flange, which depends on the design criteria of the original Sheehan knee. The crest of the patella was chosen relatively long for a good guidance in the groove of the flange and the two facettes are concave in both directions having larger arcs than the gliding surfaces of the flange. The patella prosthesis is plugged with three pegs into the resected patella remainder. No cement is used. The pegs are $8 \mathrm{~mm}$ high and $5 \mathrm{~mm}$ in diameter. They are positioned on a circle with a radius of $10 \mathrm{~mm}$.

The flanges of both sizes of the femoral component incorporate two arcs blending with the main arc of the original prosthesis. The bearing runner-like surfaces of the prosthesis change into the groove shaped flange, the bottom of which is wide enough to allow a physiological side to side movement of the patella prosthesis. The long axis of the groove builds a valgus angle of $3.5^{\circ}$ with the condylar plane.

The stem of the modified femoral component was chosen thicker than in the original design for better guidance in the medullary cavity of the distal femur. The characteristics of the design are shown in Fig. 2. 


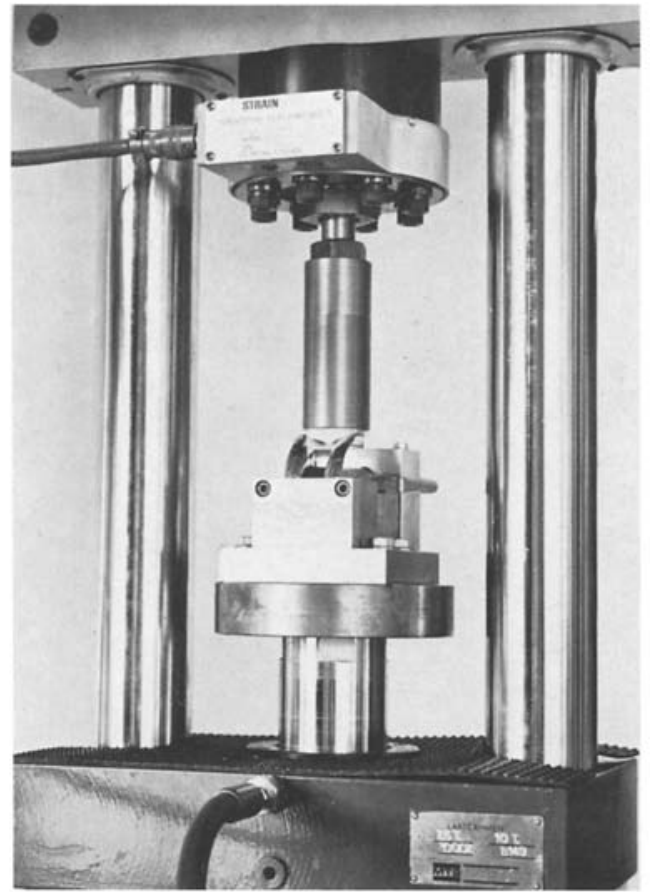

Fig. 3. Experimental set-up showing the prosthesis in the MTSmachine

\section{Tests of the Design}

Morrison [30] calculated the forces on the quadriceps tendon for various activities. Up ramp walking showed a maximum of $1.335 \mathrm{~N}$, down ramp $2.447 \mathrm{~N}$, upstairs and downstairs maxima of $2.002 \mathrm{~N}$ and $1.870 \mathrm{~N}$ were found. From these data we estimated the patellofemoral force to be $1.225 \mathrm{~N}$ at $30^{\circ}$ of flexion. Harrington [17] measured a maximal quadriceps force of $1.718 \mathrm{~N}$ against $249 \mathrm{~N}$ in patients bearing a FreemanSwanson knee arthroplasty. On the base of these findings the patellofemoral force was estimated to reach $890 \mathrm{~N}$. Bandi [4] reported calculations of the patellofemoral force of $250-1.000 \mathrm{~N}$. Perry et al. [31] found a femoropatellar force of approximately $500 \mathrm{~N}$ at $30^{\circ}$. Engin [11] calculated this force to reach maximally $300 \mathrm{~N}$. Seedhom and Terayama [37] measured the knee forces getting out of a chair with and without aid of the arms and estimated the maximum force at $250 \mathrm{~N}$ in the patellofemoral articulation at $30^{\circ}$ flexion. Maquet [23] used a calculation model which was simplified in comparison with that of Morrison and found the patellofemoral force to be three times body weight at the beginning of the stance phase. The results stated above are widely scattered. Having these values in mind and supposing that the calculations of Maquet are too high due to the simplifications (partial neglect of hamstrings and gastrocnemius) for the tests on the modified Sheehan prosthesis the femoropatellar

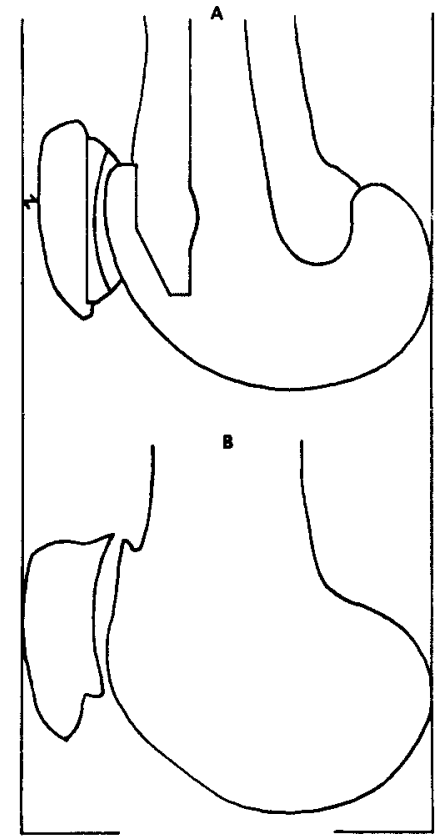

Fig. 4. The overall depth of implant and bone (A) should never exceed the total depth of the femoral condyles and the patella (B), it should rather be a little less

force was considered not to exceed the relatively high value of $1.500 \mathrm{~N}$ by any means.

For the smallest cross-section of the femoral flange a stress calculation was carried out resulting in a maximum of $226.5 \mathrm{~N} / \mathrm{mm}^{2}$, which is far below the fatigue strength of the material (cast Co-Cr-Mo alloy).

The femoral component was placed in a $100 \mathrm{kN}$. MTS testing machine and the ultra-high molecular weight polyethylene patella implant was used as indenter. The load was applied $15 \mathrm{~mm}$ from the smallest cross-section of the femoral flange, a simulation of especially adverse conditions which will probably not occur to that extent under physiological circumstances.

The load varied sinusoidally between 200 and $1.500 \mathrm{~N}$ over $10 \times 10^{6}$ cycli and was recorded. After $5 \times 10^{6}$ and $10 \times 10^{6}$ cycli the specimen was penetrated with ARDROX $970 \mathrm{P} 1$ and inspected under UV-light.

As a result of the experiment no deformation of the implant and no hair crack on the surface of the flange could be detected, hence the specimen was in the same condition as before the experiment. Figure 3 shows the experimental set-up.

\section{Surgical Procedure}

The operation is performed under pneumatic tourniquet unless diminished circulation has to be regarded as contraindication. The knee joint is draped in the usual manner. A longitudinal 


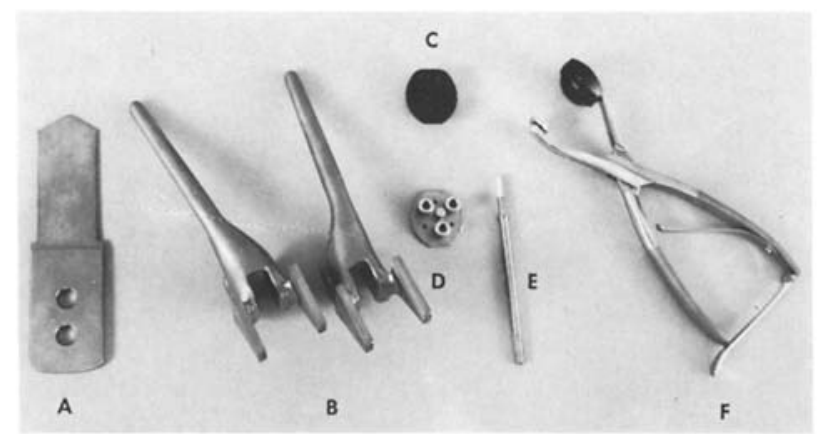

Fig.5. Showing the additional instruments: osteotome (A), right and left femoral trial component with quide for the osteotome (B), trial patella (C), drilling template (D), drill (E) and patella forceps $(F)$

median parapatellar incision is used passing straight upwards for 8 to $10 \mathrm{~cm}$ above the upper patella pole and distally bending slightly laterally towards the tibial tubercle ending one finger wide distally and medially to the tuberosity. The exposition of the joint is carried out under careful coagulation of all vessels, especially the inferior geniculate vessels. The vastus medialis is thereby incised but in the upper portion it is easily possible to bluntly separate the muscular fibers along their course up to the proximal end of the incision. The attachment of the patellar tendon is sharply exposed. The patella is dislocated laterally and completely rotated while the knee is flexed to between $120^{\circ}$ and $130^{\circ}$. If there is any structure under tension during this procedure, soft tissue release mostly in the region of the upper recess has to be accomplished first. Positioning of the femoral jig, drilling of the cortex, introduction of the aligning rod, marking the outline of the inverted $U$ on the femur, resection of the bone block and preparation of the medullary cavity with the femoral reamer is carried out exactly in the way described by Sheehan [39].

As the femoral stem of the modification is thicker than in the original prosthesis, the proximal part of the medullary canal is widened with a tapering drill very gently. The trial femoral component is introduced.

The tibial jig is inserted according to the original method at $90^{\circ}$ flexion and the cortex of the tibial head is drilled, the jig is then removed. The two flanges of the femoral trial component are equipped with gutters for both sizes of the femoral implant. An osteotome is introduced in one or other gutter and the resection line on the anterior aspect of the femur is marked. The resection is completed with the oscillating jig saw. The resection plane should ideally meet the anterior cortex of the femoral shaft.

Then two thirds of the posterior part of the condyles are removed.

Between the intracondylar gap and the anterior incision a small amount of bone has frequently to be resected so that the femoral component can be pushed into correct position.

The preparation of the tibia entirely follows the original method,

Both the tibial and femoral prosthesis are inserted and linked and the final position of both components is determined. Then the removal of osteophytes and hemiresection of the patella is carried out with the oscillating saw. The amount of resection on the patella should correspond to the thickness of the implant or even be insignificantly more. After implantation the overall

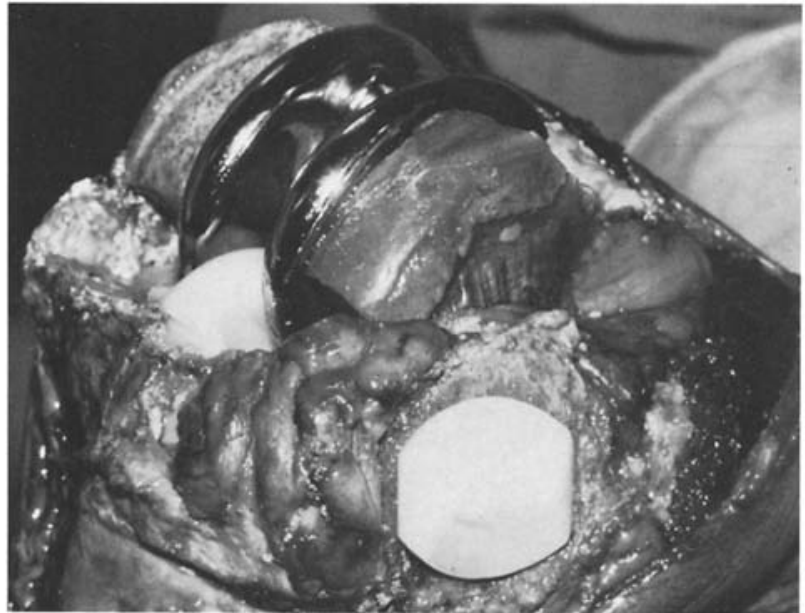

Fig. 6. Showing the adjustment of all components

distance between the anterior surface of the patella and the posterior horns of the prosthetic bearings may never exceed the corresponding distance of the natural knee, it should be even somewhat less (Fig. 4). The trial patella with its pin is pressed into the center of the resected plane. The knee is extended and the patella reduced. The rotatory adjustment of the trial patella is determined as the knee is moved through a range of flexion and extension under visualisation. When the exact position is achieved a marker is cut into the rim of the patella remainder corresponding to the marker on the trial patella. After dislocation of the patella the trial patella is replaced by the drilling template and the fixation holes, are then drilled, two proximally and one distally. The patella prosthesis is firmly pressed with the fixation forceps into the fixation holes. In some small patellae with an insufficient thickness to allow the implant to lie flush against the resection plane it can be necessary to shorten the pegs with a Lüer type forceps. Tibial and femoral component are cemented separately in the usual manner. Neomycin diluted in physiological saline is used every quarter hour throughout the operation and during setting of the cement. After release of the tourniquet all major bleeding vessels are identified and diathermised. The wound is closed in layers using two intraarticular vacuum drains and one epifascial drain. The skin is closed by an intracutanous $4 / 0$ nylon suture. A bulky dressing is applied and the leg is placed in a foam splint. The postoperative treatment with this modification does not differ from the original method.

The set of additional instruments is shown in Fig. 5. For overall alignment see Figs. 6 and 7.

\section{Material}

Since June 197816 patients have been treated with the modified Sheehan knee. In all cases severe osteoarthritis of the knee particularly accompanied by advanced alterations of the patellofemoral compartment was the indication. The procedure was never hampered by technical difficulties or other complications. The patients are reviewed in regular intervalls and no complications related to patella replacement have occurred until now. 

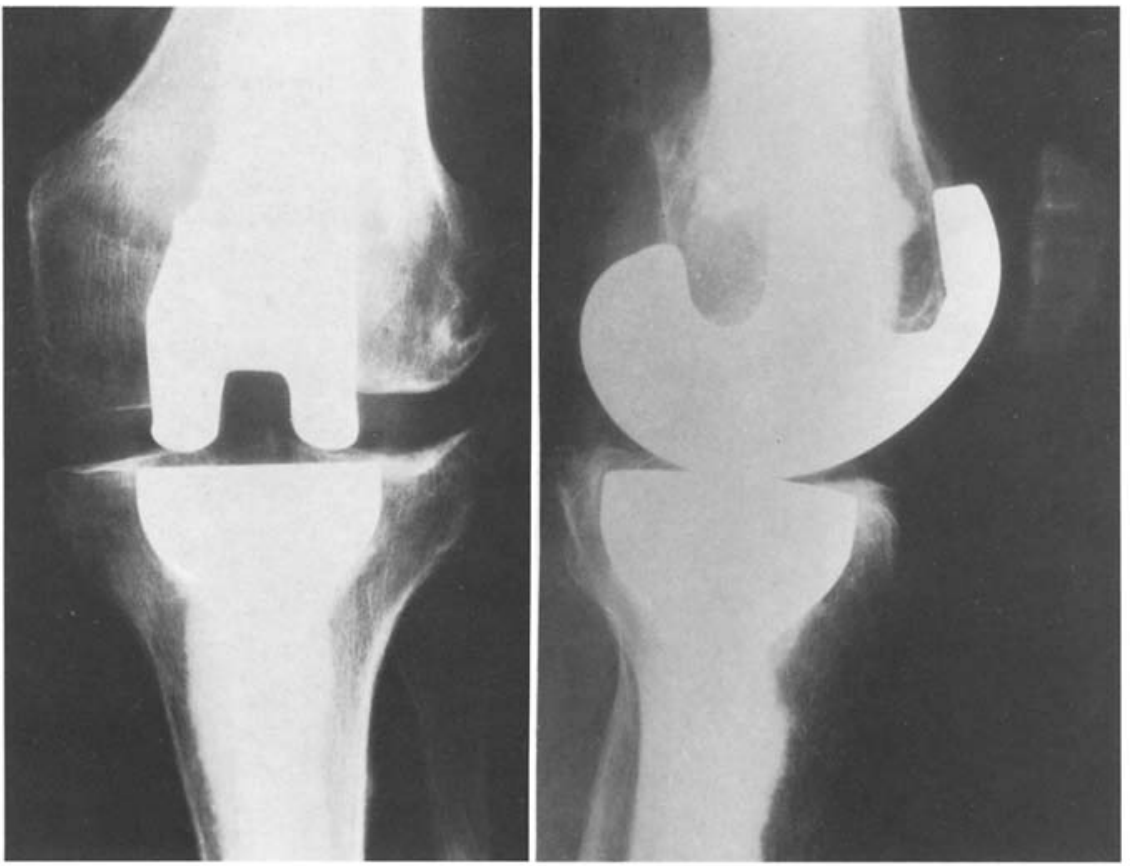

Fig. 7. Showing the postoperative radiograph of the modified Sheehan knee

\section{Discussion}

As persisting patella pain in many different knee arthroplasties remains a serious problem and long term results of patella replacement in combination with fully constrained knee prostheses indicate only slight advantages due to high stresses on the extensor mechanism an attempt was made to combine prosthetic replacement of the patellofemoral joint with the Sheehan knee arthroplasty. Sheehan points out a number of inherent problems. The control over the correct function of the collateral ligaments might no longer be possible flexing the knee and, if an implant including the patellofemoral compartment is adjusted flush to the anterior aspect of the femur, physiological knee movement and tautness of the collateral ligaments should not be maintained throughout the whole range of extension and flexion unless a large number of different sizes of the femoral component would be available. However, the measurements on cadaver femora indicated that two sizes can cover the vast majority of individual knees without neglecting the postulates mentioned above. It is true that in contrary to the original design, which is enclosed in the bone to a considerable extent the modification has an anterior flange located rather superficially. Nevertheless it has to be stressed that the indication for additional patella replacement with the Sheehan knee shall be definitely restricted to advanced osteoarthritis. In rheumatic patients problems related to skin and soft tissues might arise, and besides that in rheumatoid arthritis postoperative patellofemoral pain rarely occurs. In our follow-up series $58 \%$ of the rheumatic knees were absolutely painfree postoperatively, but only $30 \%$ of the cases with osteoarthritis. As no indication is seen for rheumatoid arthritis, there is no need for an extra small femoral component which is necessary in other designs for treatment of Still's disease and extremely small rheumatic knees. However, dealing with this problem we see a demand for a smaller version of the original Sheehan knee. For excessively large osteoarthritic knees there might be an extra large modified femoral component necessary, which is available but only on request. However, we have not yet had any demand for such a version. The fixation of the patella prosthesis with three non-cemented pegs into the remnant of the patella rarely caused complications in our series of 57 cases prior to the modified Sheehan knee. Two loosenings were observed, both due to surgical error. The amount of resection on the patella had been too great. In both cases the patella implant was removed. According to these results there was no different fixation chosen in connexion with the Sheehan prosthesis. Furthermore the non-cemented fixation of the patella has advantages in salvage procedures. But for those preferring cement technique a patella implant requiring bone cement is considered to be made available.

The mechanical tests on the modification did not show any fatigue of the material, indicating a sufficient stability of the design. 
The present series of additional patella replacement with the Sheehan knee is still too small and the followup time is not long enough to report on detailed results. Yet, as no complications arose until now, we feel encouraged to put this alternative version of the Sheehan knee arthroplasty up to discussion.

Acknowledgements. Dr. R. Miehlke wishes gratefully to acknowledge the help of Prof. Ir. R. Bosma and Prof. Dr. Ir. D. van Campen from the Twente University of Technology, Enschede, the Netherlands, who offered their facilities related with the development of the design and the laboratory tests and initiated the collaboration with Ir. H. W. Croon.

\section{References}

1 Aglietti P, Insall JN, Walkur PS, Trent P(1975) A new patella prosthesis. Design and applıation. Clin Orthop 107:175

2 Alnot JH, Aubriot J (1971) Arthroplastie totale du genou: la prothèse Guépar. Rev Chir Orthop 57:575

3 Attenborough CG (1978) The Attenborough total knee replacement. J Bone Jt Surg 60-B:320

4 Bandi W (1972) Chondromalacia patellae und femoropatellare Arthrose. Helv Chir Acta Suppl II

5 Bargren JH, Freeman MAR, Swanson SAV, Todd RC (1976) Arthroplasty in the treatment of arthritic knee. A 2-4 year review. Clin Orthop 120:65

6 Bechtol CO (1976) Type I. Patello-femoral replacement. Pamphlet of Richards Manufacturing Co., Inc.

7 Blazina ME, Fox JM, Del Pizzo W, Broukhim B, Ivey FM (1979) Patellofemoral replacement. Clin Orthop 144:98

8 Coventry MB (1977) Anametric knee prosthesis. Pamphlet of Howmedica, Inc

9 Deburge A, GUEPAR (1976) Guepar hinge prosthesis. Complications and results with two years' follow-up. Clin Orthop 120:47

10 DePalma AF, Sawyer B, Hoffman DJ (1960) Reconsideration of lesions affecting the patellofemoral joint. Clin Orthop 18:63

11 Engin AE (1976) Experimental determination of the patellofemoral joint forces. Proc. 29th ACEMB, Boston, 111

12 Erkman MJ, Walker PS (1974) A study of knee geometry applied to the design of condylar prosthesis. Biomed Eng 9: 14

13 Freeman MAR, Todd RC, Bamert P, Day WH (1978) ICLH arthroplasty of the knee: 1968-1977. J Bone Jt Surg 60-B:339

14 Groeneveld HB, Schöllner D, Bantjes A, Feijen J (1971) Eine Kniegelenkstotalendoprothese unter Erhaltung der Kreuz- und Seitenbänder. Z Orthop 109:599

15 Groeneveld HB, Schöllner D (1973) Die Patellarückflächenprothese - eine Ergänzung zur Kniegelenkstotalalloarthroplastik. Arch Orthop Unfall Chir 76:205

16 Hanslik L, Scholz J (1978) Der alloplastische Ersatz der Kniescheibengelenkfläche nach McKeever. Z Orthop 116:7

17 Harrington IJ (1976) A bio-engineering analysis of force actions at the knee in normal and pathological gait. Biomed Eng 11:167

18 Insall J, Scott WN, Ranawat CS (1979) The total condylar knee prosthesis. A report of two hundred and twenty cases. J Bone Jt Surg 61-A : 173

19 Lacey JA (1978) A statistical review of 100 consecutive "U.C.I." low friction knee arthroplasties with analysis of results. Clin Orthop 132:163
20 Levitt RL (1973) A long-term evaluation of patellar prosthesis. Clin Orthop 97:153

21 Lubinus HH (1979) Patella glide bearing total replacement. Orthopedics 2:119

22 Lunceford EM (1969) Femoral condyle replacement. Howmedica Prod. Bulletin 95

23 Maquet PGJ (1976) Biomechanics of the knee. With application to the pathogenesis and the surgical treatment of osteoarthritis. Springer, Berlin Heidelberg New York

24 McKeever DC (1955) Patellar prosthesis. J Bone Jt Surg 37-A: 1074

25 Mensch JS, Amstutz HC (1975) Knee morphology as a guide to knee replacement. Clin Orthop 112:231

26 Miehlke R (1979) Der heutige Stand der Kniegelenksendoprothetik. Therapiewoche 29:6676

27 Miehlke R, Schwenen M (1980) Beurteilung von Kniegelenkendoprothesen im Röntgenbild. Z Orthop 118:1

28 Miehlke R (1980) Resultate und Komplikationen bei Scharnierendoprothesen des Kniegelenks in der Therapie rheumatischer Erkrankungen. Verh Dtsch Ges Rheumatol 6:488

29 Miehlke R (1980) Erste Erfahrungen und Ergebnisse mit der Kniegelenksendoprothese nach Sheehan in der Therapie rheumatischer Erkrankungen. Verh Dtsch Ges Rheumatol $6: 495$

30 Morrison GB (1969) Function of the knee joint in various activities. Biomed Eng 4:573

31 Perry J, Antonelli D, Ford W (1975) Analysis of knee joint forces during flexed knee stance. J Bone Jt Surg 57-A:961

32 Platt G (1966) Arthroplasty of the knee in rheumatoid arthritis. J Bone Jt Surg 48-B: 179

33 Ritter H (1974) Kritik an einer Kniegelenkstotalprothese, Konstruktion, Funktion und klinische Bewährung (die Guépar-Prothese). Arch Orthop Unfall Chir 78:136

34 RMC (1978) Total knee system. Pamphlet of Richards Manufacturing Co Inc

35 Sbarbaro JL (1973) Femoral condylar mold arthroplasty in 150 rheumatoid knees. Acta Orthop Belg 39:138

36 Seedhom BB, Longton EB, Wright V, Dowson D (1972) Dimensions of the knee. Radiographic and autopsy study of sizes required for a knee prosthesis. Ann Rheum Dis 31:54

37 Seedhom BB, Terayama K (1976) Knee forces during the activity of getting out of a chair with and without the aid of arms. Biomed Eng 11:278

38 Sheehan JM (1978) Arthroplasty of the knee. J Bone Jt Surg 60-B: 333

39 Sheehan JM (1978) Manual of knee arthroplasty. Published by Deloro Surgical

40 Thomas W, Grundei H (1979) Die anatomische GT-Schlittenprothese Lübeck. Z Orthop 117:67

41 Turner RH, Aufranc OE (1969) Femoral stem replacement arthroplasty of the knee. Surg Clin North Am 49:917

42 Vermeulen H, DeDonker E, Watillon M (1973) Les prothèses rotuliennes de McKeever dans l'arthrose femoropatellaire. Acta Orthop Belg 39:79

43 Walldius B (1957) Arthroplasty of the knee using an endoprosthesis. Acta Orthop Scand Suppl 24:78

44 Worrell RV (1979) Prosthetic resurfacing of the patella. Clin Orthop 144:91

45 Zöfelt R (1978) Röntgenometrische Untersuchungen am Kniegelenk als Grundlage zur Konstruktion einer scharnierfreien Kniegelenks-Total-Endoprothese. Dissertation, Universität Münster

Received May 8, 1980 